\title{
Utilization of Palm Oil Shell Waste as Alternative Additives in Manufacturing Paving Block
}

\section{Pemanfaatan limbah Cangkang Kelapa Sawit Sebagal Alternatif Bahan Tambah Dalam Pembuatan Paving Block}

\author{
Wiratno $^{(1)}$ Samuel Layang ${ }^{(2)}$ Wandra Prima Pera $^{(3)}$ \\ 1), 2), 3) Pendidikan Teknik Bangunan, Fakultas Keguruan dan Ilmu Pendidikan Universitas Palangka Raya \\ Kampus UPR Tunjung Nyaho Jl. H. Timang, 73111A \\ e-mail:pak.wiratno@gmail.com
}

\begin{abstract}
Palm shells are one of the wastes produced from the processing of crude palm oil in addition to empty fruit bunches and coir which account for $60 \%$ of oil production. Palm oil shell waste is widely used as active charcoal in the oil, rubber, sugar, and pharmaceutical industries. The potential of palm oil shell waste in Indonesia is very large considering the area of oil palm plantations which continues to increase every year. This study aims to determine the percentage of the addition of palm oil shell waste in the manufacture of paving blocks that provide optimum compressive strength and water absorption values from several variations of the addition of palm oil shell waste that replaces some of the fine aggregates. The study was carried out experimentally in a laboratory using a boxed specimen with a length of $20 \mathrm{~cm}$, a width of $10 \mathrm{~cm}$, a height of $6 \mathrm{~cm}$ by 40 pieces. The mixture uses a ratio of 1 cement and 5 sand with fas 0.3. Treatment of test specimens by immersion in water for further testing of compressive strength and absorption at the age of 28 days. Based on testing of the compressive strength of paving blocks with a percentage of $0 \%, 5 \%, 10 \%, 15 \%$ are respectively $8.08 \mathrm{MPa}, 7.18 \mathrm{MPa}, 6.46 \mathrm{MPa}, 5.94 \mathrm{MPa}$. The value of paving block water absorption with a percentage of $0 \%, 5 \%, 10 \%, 15 \%$ are respectively $9.88 \%, 10.25 \%$, $12.27 \%, 12.44 \%$
\end{abstract}

Keywords: oil palm shell, compressive strength, absorption

\begin{abstract}
ABSTRAK
Cangkang kelapa sawit merupakan salah satu limbah yang dihasilkan dari pengolahan minyak kelapa sawit (crude palm oil) selain tandan buah kosong dan sabut yang jumlahnya mencapai $60 \%$ dari produksi minyak. Limbah cangkang kelapa sawit banyak dimanfaatkan sebagai arang aktif pada industri minyak, karet, gula dan farmasi. Potensi limbah cangkang kelapa sawit di Indonesia sangat besar mengingat areal perkebunan kelapa sawit yang terus meningkat setiap tahunnya. Penelitian ini bertujuan untuk mengetahui prosentase penambahan limbah cangkang kelapa sawit dalam pembuatan paving block yang memberikan nilai kuat tekan optimum dan nilai penyerapan air dari beberapa variasi penambahan limbah cangkang kelapa sawit yang menggantikan sebagian agregat halus. Penelitian dilakukan secara eksperimental di laboratorium menggunakan benda uji kotak dengan ukuran panjang $20 \mathrm{~cm}$, lebar 10 $\mathrm{cm}$, tinggi $6 \mathrm{~cm}$ sebanyak 40 buah. Campuran menggunakan perbandingan 1 semen dan 5 pasir dengan fas 0,3 . Perawatan benda uji dengan cara direndam dalam air untuk selanjutnya dilakukan pengujian kuat tekan dan penyerapan pada umur 28 hari. Berdasarkan pengujian nilai kuat tekan paving block dengan prosentase $0 \%, 5 \%, 10 \%, 15 \%$ berturut-turut sebesar 8,08 $\mathrm{MPa} ; 7,18 \mathrm{MPa} ; 6,46 \mathrm{MPa} ; 5,94 \mathrm{MPa}$. Nilai serapan air paving block dengan prosentase $0 \%, 5 \%, 10 \%, 15 \%$ berturut-turut sebesar $9,88 \%$; $10,25 \% ; 12,27 \% ; 12,44 \%$.
\end{abstract}

Kata kunci: cangkang kelapa sawit, kuat tekan, penyerapan

\section{PENDAHULUAN}

Teknologi bahan mengalami perkembangan yang sangat berarti seiring dengan meningkatnya pengetahuan manusia akan sifat-sifat dari berbagai jenis-jenis bahan. Hal ini tentunya akan memberikan konstribusi yang sangat bermanfaat bagi kehidupan manusia. Saat ini pengembangan ilmu pengetahuan dan teknologi mengarah kepada pengembangan yang berkelanjutan (sustainable development) dan ramah lingkungan. Oleh kerena itu pemakaian bahan atau material juga cenderung mengarah kepada sesuatu yang lebih ramah lingkungan seperti pemakaian bahanbahan sisa atau limbah.

Penggunaan material limbah sebagai bahan tambah atau pengganti telah banyak dilakukan seperti penggunaan pada campuran beton. Beton merupakan batuan buatan yang dibentuk dari semen portland ( $p c)$, agregat halus, agregat kasar dan air dengan atau tanpa bahan tambahan. Penggunaan material limbah dalam campuran beton dimungkinkan karena material limbah 
tersebut memiliki sifat yang mirip dengan material utama pembentuk beton.

Beberapa contoh material limbah yang dapat digunakan dalam campuran beton antara lain abu terbang (fly ash), abu sekam padi, cangkang sawit, limbah serat besi, serat plastik (polypropylene). Penggunaan limbah tersebut dapat mengurangi penggunaan semen, agregat halus dan agregat kasar. Selain itu dapat pula untuk memperbaiki sifat beton seperti memberikan nilai kuat tekan yang lebih tinggi, beton menjadi lebih kedap air. Lebih lanjut pemanfaatan limbah sebagai campuran dalam pembuatan beton akan membantu mengurangi dampak negatif yang ditimbulkan oleh keberadaan limbah.

Dari beberapa contoh limbah yang disebutkan di atas, cangkang kelapa sawit merupakan limbah yang relatif banyak khususnya di daerah yang memiliki perkebunan kelapa sawit. Perkebunan kelapa sawit di Indonesia terus bertambah dari segi luas lahan. Berdasarkan data Statistik Kelapa Sawit Indonesia tahun 2016 yang dikeluarkan oleh Badan Pusat Statistik Indonesia, luas area kelapa sawit dari Perusahaan Perkebunanan Besar Indonesia sejak tahun 1999 sampai tahun 2015 menunjukkan peningkatan setiap tahun. Hingga tahun 2015, luas areal kelapa sawit yang dikelola oleh Perkebunan Besar Negara dan Perkebunana Besar Swasta mencapai 6.724.876 ha. Menurut data BPS Provinsi Kalimantan Tengah tahun 2016 (Tabel 1), areal perkebunan kelapa sawit mencapai $1.495 .605,89$ ha dengan produksi kelapa sawit sebesar 4.454.675,65 ton.
Produk utama dari kelapa sawit yaitu minyak sawit mentah (crude palm oil) yang digunakan sebagai bahan baku dalam industri pembuatan minyak goreng, mentega, sabun, pelumas, cream kulit, campuran bahan bakar biodiesel dan masih banyak lagi produk turunannya. Proses ekstraksi buah kelapa sawit menjadi minyak sawit kasar akan menghasilkan limbah berupa tandan buah kosong, sabut dan cangkang sawit.

Cangkang kelapa sawit yang dihasilkan dari pengolahan minyak kelapa sawit mencapai $60 \%$ dari produksi minyak. Limbah cangkang kelapa sawit banyak dimanfaatkan sebagai arang aktif pada berbagai industri seperti industri minyak, karet, gula dan farmasi. Selain itu cangkang sawit digunakan sebagai bahan bakar pembangkit tenaga uap dan bahan pengeras jalan.

Penelitian yang mengggunakan limbah hasil ekstraksi kelapa sawit dalam bidang konstruksi telah banyak dilakukan. Penggunaan abu serat kelapa sawit (palm oil fibre ash) dan abu cangkang kelapa sawit (palm oil shell ash) sebagai agregat pengisi pada campuran hot rolled sheet-base berpotensi tahan terhadap deformasi. Pemanfaatan abu cangkang dan serat kelapa sawit dari boiler untuk pembuatan beton ringan memenuhi syarat minimum untuk beton ringan struktural $(6,89 \mathrm{MPa})$ dan mempunyai berat isi kurang dari berat maksimal yang disyaratkan sekitar 1400 $\mathrm{kg} / \mathrm{m}^{3}$. Penggunaan Bongkahan Cangkang Sawit (BCS) sebagai bahan pengisi agregat kasar pada beton dapat menghasilkan nilai kuat tekan rata-rata beton sebesar $163,111 \mathrm{~kg} / \mathrm{cm}^{2}$.

Tabel 1. Luas Area Perkebunan dan Produksi Kelapa Sawit Provinsi Kalimantan Tengah

\begin{tabular}{ccc}
\hline Tahun & Luas Area Perkebunan (ha) & Produksi Kelapa Sawit (ton) \\
\hline 2012 & 1.164 .009 .41 & $5.005 .252,23$ \\
\hline 2013 & 1.185 .592 .51 & $3.200 .920,15$ \\
\hline 2014 & $1.297 .886,17$ & $3.574 .899,33$ \\
\hline 2015 & $1.339 .832,43$ & $5.436 .462,21$ \\
\hline 2016 & 1.495 .605 .89 & $4.485 .167,20$ \\
\hline
\end{tabular}

Sumber: BPS Provinsi Kalimantan Tengah, 2017

\section{METODE PELAKSANAAN}

\section{A. Material}

1. Semen

Semen portland ( $\mathrm{pc}$ ) merupakan semen hidrolis yang dihasilkan dengan cara menggiling terak semen portland terutama yang terdiri atas kalsium silikat yang bersifat hidrolis dan digiling bersama-sama dengan bahan tambahan berupa satu atau lebih bentuk kristal senyawa kalsium sulfat dan boleh ditambah dengan bahan tambahan lain. Semen yang digunakan adalah semen portland pozzolan (PPC) tipe I yang diproduksi PT. Semen Gresik

2. Agregat halus
Agregat halus merupakan pasir alam sebagai hasil disintegrasi alami batuan atau pasir yang dihasilkan oleh industri pemecah batu dan mempunyai ukuran butir terbesar 5,0 mm [6]. Agregat halus (pasir alam) berasal dari Tangkiling

\section{Cangkang kelapa sawit (cks)}

Cangkang kelapa sawit (palm kernel shell) sering juga disebut tempurung sawit adalah bagian keras yang terdapat pada buah kelapa sawit yang berfungsi melindungi isi atau kernel dari buah sawit tersebut. Limbah cangkang kelapa sawit yang digunakan adalah kelapa sawit jenis Tenera, dari perkebunan sawit milik PT. Multi Persada Gatra Megah, yang berada di km 41 Jalan Trans Muara Teweh - Puruk Cahu, Kabupaten 
Barito Utara Provinsi Kalimantan Tengah (ditunjukkan pada Gambar 1).

4. Air

Air merupakan bahan dasar pembuat campuran mortar yang penting. Fungsi air dalam campuran mortar antara lain adalah sebagai bahan pencampur dan pengadukan antara semen dan agregat. Pada umumnya air yang dapat diminum dan memenuhi persyaratan sebagai air tidak mengandung minyak, asam, alkali, zat organik, atau bahan lainnya yang dapat merusak beton. Sifat fisik agregat halus dan cangkang kelapa sawit (cks) ditunjukkan pada Tabel 2.

\section{B. Proporsi campuran}

Perbandingan campuran semen dengan pasir untuk pembuatan paving block yang digunakan 1:5 dengan perbandingan air semen (fas) 0,3 ditunjukkan pada Tabel 3. Benda uji paving block dibuat 4 macam variasi penambahan limbah cangkang kelapa sawit $(0 \%$, $5 \%, 10 \%, 15 \%)$ terhadap volume pasir, masing-masing variasi sebanyak 10 benda uji.

C. Pembuatan, perawatan dan pengujian

Benda uji yang digunakan berbentuk kotak dengan ukuran panjang $20 \mathrm{~cm}$, lebar $10 \mathrm{~cm}$, tinggi 6 $\mathrm{cm}$. Adukan bahan paving block dimasukkan kedalam cetakan paving block yang sebelumnya pada bagian dalam cetakan diberi minyak pelumas. Setelah adukkan dimasukan kedalam cetakan maka dilakukan press dengan kekuatan tekan tenaga manusia untuk pemadatan paving block.

Perawatan dilakukan setelah paving block mencapai final setting, artinya paving block telah mengeras. Perawatan benda uji dalam penelitian ini dilakukan dengan cara merendam seluruh permukaan paving block didalam bak perendam yang berisi air, untuk mencegah terjadinya keretakan karena kehilangan air.

Pengujian dilakukan pada umur 28 hari untuk mengetahui nilai kuat tekan dan penyerapan paving block. Pengujian kuat tekan paving block mengacu pada SNI 03-0691-1996 dengan menggunakan alat Compression Testing Machine. Paving block yang telah berumur 28 hari dan dalam kondisi kering dimasukkan kedalam oven dengan suhu $105^{\circ} \mathrm{C}$ selama 24 jam. Setelah 24 jam Paving block dikeluarkan dan didinginkan. Paving block kering ditimbang beratnya $\left(w_{k}\right)$. Kemudian dilanjutkan dengan merendam selama 24 jam. Setelah 24 jam, paving block diangkat dan ditimbang beratnya $\left(w_{b}\right)$.

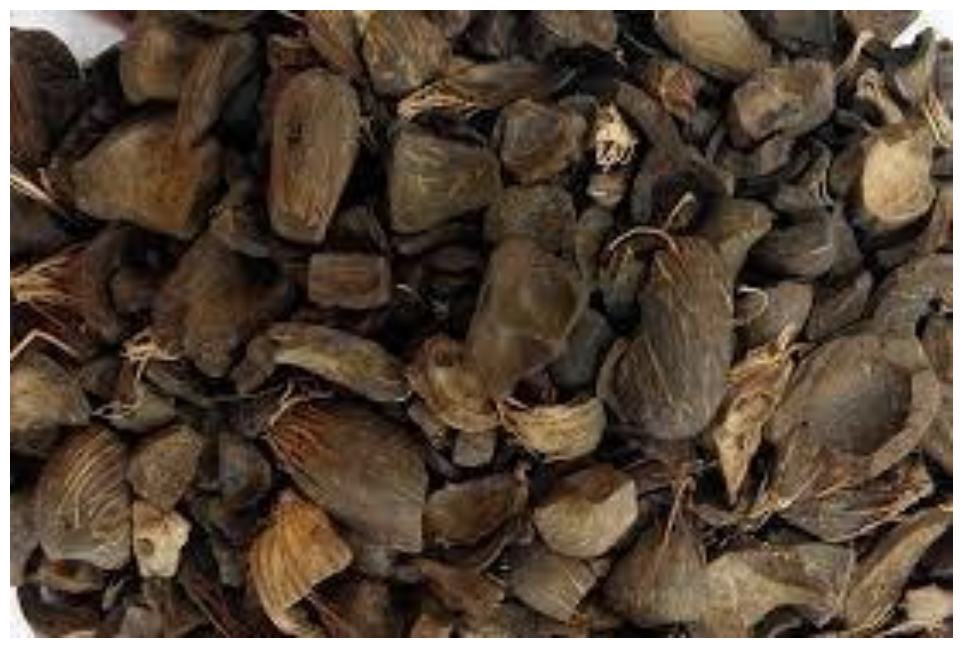

Gambar 1 Cangkang Kelapa Sawit

Tabel 2. Sifat Fisik Agregat Halus dan cks

\begin{tabular}{lcc}
\hline \multicolumn{1}{c}{ Sifat } & Agregat Halus & cks \\
\hline Modulus Kehalusan & 3,48 & - \\
\hline Zona Gradasi & Zona 2 & - \\
\hline Berat Jenis (SSD) & $2,45 \%$ & $2,84 \%$ \\
\hline Penyerapan (Absorbsi) & $3,34 \%$ & $1,82 \%$ \\
\hline Berat isi & $1706,04 \mathrm{~kg} / \mathrm{m}^{3}$ & \\
\hline Kadar Air Rata-Rata & 2,11 & - \\
\hline Kadar Zat Organik & $20-25 \%$ & - \\
\hline Kadar Lumpur & $1,54 \%$ & - \\
\hline Sumber: Hasil Pengujian, 2018 & &
\end{tabular}


Tabel. 3 Proporsi Campuran

\begin{tabular}{ccccc}
\hline $\begin{array}{c}\text { Material } \\
\mathbf{~ k g} / \mathbf{m}^{\mathbf{3}}\end{array}$ & $\mathbf{5}$ & Prosentase Penambahan cks (\%) \\
\cline { 2 - 5 } Semen & 525,50 & $\mathbf{5}$ & $\mathbf{1 0}$ & $\mathbf{1 5}$ \\
\hline Ag.halus & 1421,70 & 525,50 & 525,50 & 525,50 \\
\hline Air & 1751,67 & 1350,62 & 1279,53 & 1208,45 \\
\hline cks & 0 & 1751,67 & 1751,67 & 1751,67 \\
\hline Sumber: Hasil Perhitungan, 2018 & 71,09 & 142,17 & 213,26 \\
\hline
\end{tabular}

\section{HASIL DAN PEMBAHASAN}

\section{Kuat Tekan}

Hasil pengujian kuat tekan paving block pada umur 28 hari seperti pada Tabel 4. Kuat tekan paving block (Umur 28 Hari) akan semakin menurun dengan bertambahnya jumlah tempurung kelapa sawit dalam campuran. Kuat tekan tertinggi terjadi pada campuran tempurung kelapa sawit $0 \%$ sebesar $8,08 \mathrm{MPa}$, kemudian kuat tekan terendah terjadi pada campuran tempurung kelapa sawit 15\% yaitu sebesar 5,94 $\mathrm{MPa}$ (ditunjukkan pada Gambar 2).

Hal yang memberikan perbedaan dalam penurunan kuat tekan paving block adalah setelah paving block mengeras, air bebas dan air ikat akan keluar dari dinding paving block yang kemudian akan menguap. Panas yang terjadi pada paving block akibat reaksi antara semen dan air mengakibatkan penguapan air dari tempurung kelapa sawit akan bertambah besar dan penguapan yang terjadi tidak hanya terjadi pada air bebas saja, tetapi air ikat pada tempurung kelapa sawit akan ikut menguap. Penguapan air yang keluar dari rongga sel dan dinding sel mengakibatkan tempurung kelapa sawit akan menyusut. Penyusutan tersebut akan mengakibatkan berkurangnya lekatan yang baik antara tempurung kelapa sawit dengan pasta semen yang mengakibatkan menurunnya kuat tekan paving block.

Selain itu tempurung kelapa sawit memiliki sifatsifat kimia berupa selulosa dan lignin yang mana kandungannya yang tinggi tersebut akan menghambat proses hidrasi semen yang mengakibatkan penurunan pasta semen dan memperlemah lekatan antara pasir dengan pasta semen.

Kemungkinan lain juga nilai faktor air semen yang rendah sangat berpengaruh terhadap mutu paving block, di karenakan nilai faktor air semen yang rendah akan menyebabkan kesulitan dalam pengerjaan, yaitu kesulitan dalam pelaksanaan pemadatan yang akhirnya akan menyebabkan mutu paving block menurun.

\section{Serapan air paving block}

Hasil pengujian serapan air paving block pada umur 28 hari seperti pada Tabel 5. Serapan air paving block akan semakin meningkat dengan bertambahnya tempurung kelapa sawit dalam campuran. Serapan air terendah terjadi pada persentase tempurung kelapa sawit $0 \%$ sebesar 9,88\%, kemudian serapan air akan meningkat sampai pada persentase tempurung kelapa sawit $15 \%$ yaitu sebesar $12,44 \%$ (ditunjukkan pada Gambar 3).

Faktor yang menyebabkan terjadinya peningkatan serapan air pada paving block yaitu saat paving block direndam, air yang terdapat pada rongga sel dan dinding sel yang terdapat pada paving block akan menguap. Penguapan air disebabkan oleh panas hidrasi yang timbul akibat reaksi air dan semen, sehingga mengakibatkan volume tempurung kelapa sawit beserta serabut-serabutnya akan menyusut. Penyusutan pada tempurung kelapa sawit akan menyebabkan paving block berpori, sehingga akan memiliki daya serap air yang tinggi.

Tabel. 4 Kuat Tekan Paving Block Umur 28 Hari

\begin{tabular}{cc}
\hline \% cks & Kuat Tekan Rata-rata (MPa) \\
\hline 0 & 8,08 \\
\hline 5 & 7,18 \\
\hline 10 & 6,46 \\
\hline 15 & 5,94 \\
\hline (Sumber: Hasil Pengujian, 2018) &
\end{tabular}

Tabel. 5 Serapan Air Paving Block Umur 28 Hari

\begin{tabular}{cc}
\hline \% cks & Serapan Air Rata-Rata (\%) \\
\hline 0 & 9,88 \\
\hline 5 & 10,85 \\
\hline 10 & 12,27 \\
\hline 15 & 12,44 \\
\hline (Sumber: Hasil Pengujian, 2018)
\end{tabular}




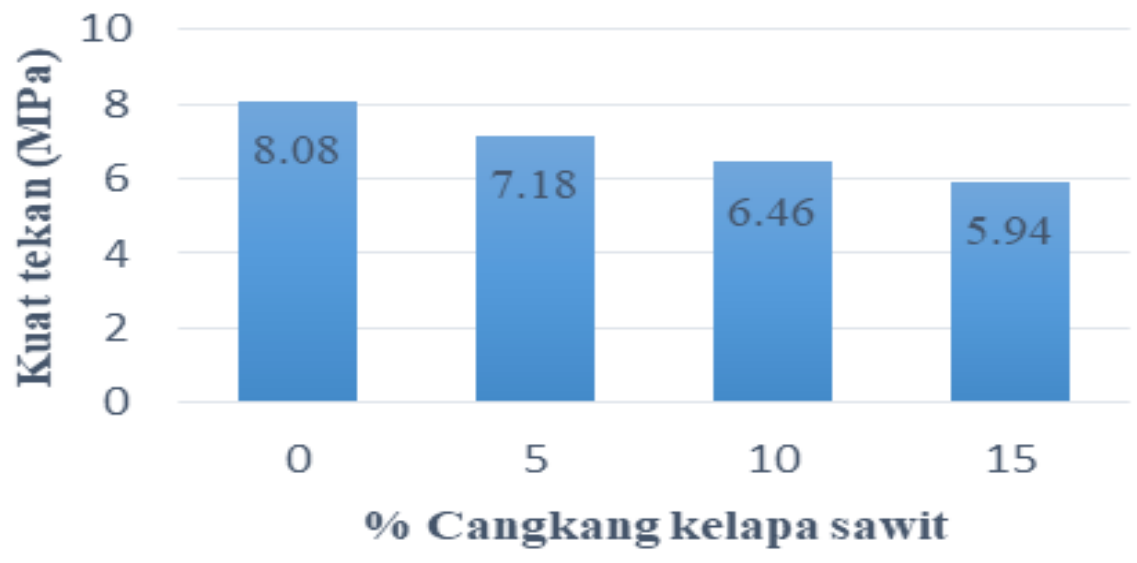

Gambar 2. Kuat Tekan Rata-Rata Umur 28 Hari

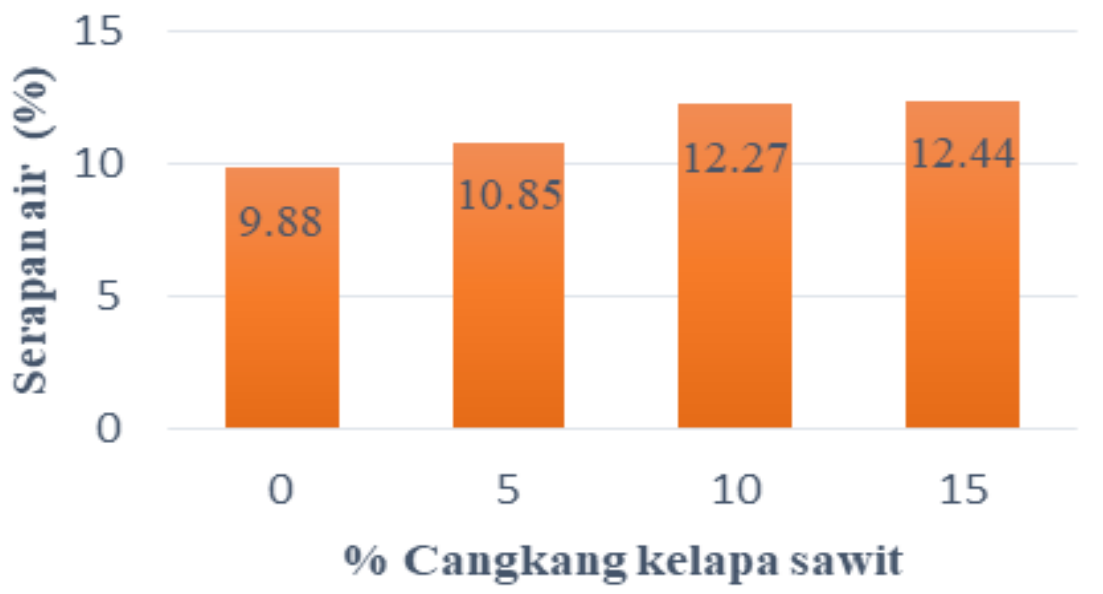

Gambar 3. Serapan Air Umur 28 Hari

\section{KESIMPULAN}

1. Paving block dengan prosentase $0 \%$ cangkang kelapa sawit menghasilkan kuat tekan terbesar

2. Kuat tekan paving block dengan prosentase $0 \%, 5 \%$, $10 \%, 15 \%$ berturut-turut sebesar 8,08 $\mathrm{MPa} ; 7,18$ $\mathrm{MPa} ; 6,46 \mathrm{MPa} ; 5,94 \mathrm{MPa}$

3. Serapan air terbesar dihasilkan oleh campuran dengan prosentase cangkang kelapa sawit 15\%

4. Serapan air paving block dengan prosentase $0 \%$, $5 \%, 10 \%, 15 \%$ berturut-turut sebesar 9,88\%; $10,85 \% ; 12,27 \% ; 12,44 \%$.

5. Penambahahan jumlah cangkang kelapa sawit dalam campuran berbanding lurus dengan serapan air namun berbanding terbalik dengan nilai kuat tekan.

\section{SARAN}

1. Perlu dilakukan penelitian lebih lanjut tentang kuat tekan dan serapan air paving block menggunakan campuran limbah tempurung kelapa sawit dengan BALANGA: Jurnal Pendidikan Teknologi dan Kejuruan ISSN 2338-426X variasi campuran semen dan pasir dan variasi faktor air semen agar diperoleh kuat tekan maupun serapan air sesuai dengan standar mutu yang diisyaratkan.

2. Diperlukan metode untuk mengolah limbah tempurung kelapa sawit agar menjadi lebih baik, sehingga kandungan zat-zat yang berpengaruh buruk pada perlekatan dan pengerasan semen dapat dikurangi.

\section{DAFTAR PUSTAKA}

B. L. Suparna, T. W. Panggabean, and S. Mude, "Potensi Penggunaan Limbah Kelapa Sawit sebagai Agregat Pengisi Pada Campuran Hot Rolled Sheet-Base," Univ. Gajah Mada, vol. 14, no. 2, pp. 87-96, 2014.

BSN, SNI 15-2049-2004 Semen Portland. BSN, 2004.

BSI, SNI 03-2847-2002: Tata Cara Perhitungan Struktur Beton Untuk Bangunan Gedung. 2002. 
Haspiadi and Kurniawaty, "Pemanfaatan Limbah Padat Abu Cangkang dan Serat Kelapa Sawit dari Boiler untuk Pembuatan Bata Beton Ringan," J. Ris. Teknol. Ind., vol. 6, no. 12, pp. 11-19, 2015.

H. Riadi and Danil, "Pemanfaatan Bahan Limbah Cangkang Sawit sebagai Bahan Pengisi Agregat
Kasar pada Beton," vol. 1, no. 117, pp. 80-85, 2010.

T. Mulyono, Teknologi Beton. Yogyakarta: Andi, 2004.

Y. Fauzi, Y. E. Widiyastuti, I. Satyawibawa, and R. H. Paeru, "Kelapa Sawit: Budidaya, Pemanfaatan Hasil dan Limbah, Analisis Usaha dan Pemasaran." Penebar Swadaya, 2002. 